\title{
The health effects of menthol cigarettes as compared to non-menthol cigarettes
}

\author{
Allison C Hoffman
}

\begin{abstract}
Since the 1920s, menthol has been added to cigarettes and used as a characterizing flavor. The health effects of cigarette smoking are well documented, however the health effects of menthol cigarettes as compared to nonmenthol cigarettes is less well studied. This review discusses menthol's effects on 1) biomarkers of tobacco smoke exposure, 2) toxicity and cellular effects, 3) lung function and respiration, 4) pulmonary and/or vascular function, 5) allergic reactions and inflammation, and 6) tobacco-related diseases. It is concluded that menthol is a biologically active compound that has effects by itself and in conjunction with nicotine, however much of the data on the other areas of interest are inconclusive and firm conclusions cannot be drawn.
\end{abstract}

\section{Introduction}

Tobacco use produces a myriad of negative health effects, and has caused more than 5 million premature deaths through diseases such as cancer, cardiovascular disease, and respiratory disease [1]. Given the large number of menthol cigarette users (nearly $27 \%$ of current smokers, with Black/African American smokers being about 3 times more likely to smoke menthol cigarettes as compared to white smokers $[2,3]$ ) there is less information on the health of effects of menthol cigarettes as compared to non-menthol cigarettes than might be expected. Indeed, although there are many research articles that point to menthol as a possible contributing factor to several health effects of smoking, the majority did not investigate menthol as an independent factor and instead focused on racial/ethnic disparities on use. This review seeks to explore the available literature on the health effects of menthol cigarettes as compared to non-menthol cigarettes. Questions addressed in this review include:

- What, if any, are menthol's effects on biomarkers of tobacco smoke exposure?

- What effect, if any, does menthol have on a cellular level?

- What effect, if any, does menthol have on respiration?

Correspondence: allison.hoffman@fda.hhs.gov

Center for Tobacco Products, Food and Drug Administration, Rockville, MD 20850, USA
- What effect, if any, does menthol have on cardiovascular function?

- What allergic reactions have been associated with menthol cigarettes?

- What effect, if any, does menthol have on smokingrelated disease?

Summarized in this review are 89 articles found to have either direct relevance to these questions, or were used to provide relevant background information. Many of these articles were identified through a review of the literature conducted by the National Cancer Institute in 2009, published as "Bibliography of literature on menthol and tobacco" http://cancercontrol.cancer.gov/ tcrb/documents/menthol_bibliography_508.pdf. Search terms used were menthol cigarette(s); mentholated cigarette(s); menthol tobacco; mentholated tobacco; menthol smoker(s); menthol AND the following terms: addiction, nicotine, marketing, cancer, biomarkers, asthma, cardiovascular disease, heart disease, vascular disease, chronic obstructive lung disease, respiratory, environmental tobacco smoke, national health, health disparities, and minority health. Additional searches and sources, such as those identified through review articles, identified additional articles that were included as appropriate. A publication or study is identified as having a tobacco industry association if one or more authors were employees of the tobacco industry, as identified by author affiliation on the publication.

Of those articles that are in the NCI Bibliography but were not included, most were not directly relevant 
to this topic (e.g., they studied menthol as a chemical independent from tobacco smoke exposure, did not evaluate menthol as a separate variable). Some of those articles, however, were used to provide background information. Animal or in vitro research was included only to help explain human findings. Although a few review articles were used to make general statements and/or provide background information, most were not included in deference to original sources. Published abstracts were not included out of concern that, due to the lack of details, those studies could not adequately be assessed.

\section{Biomarkers of tobacco smoke exposure in menthol and nonmenthol smokers Nicotine}

Inhalation of drugs is a very effective means of delivery because inhaled drugs avoid first-pass metabolism by the liver, which rapidly metabolizes nicotine through the enzyme cytochrome P450 (CYP2A6). The main metabolite of nicotine is cotinine, and cotinine concentrations in blood, urine, or saliva are often used as biomarkers to evaluate tobacco use and exposure to environmental tobacco smoke [4-6]. Cotinine has a longer half-life (average 18-20 hours) than does nicotine (2-3 hours) [5], making it a more feasible marker of tobacco use than nicotine. Cotinine is further metabolized to trans3'-hydroxycotinine (3 HC). Although glucuronidation (a process by which glucuronic acid is conjugated with a substrate) is usually a minor metabolic pathway for nicotine and cotinine, it can be a major determinant of nicotine clearance in people who have low CYP2A6 activity. That is, in people who metabolize nicotine more slowly through the CYP2A6 pathway, the glucuronidation pathway may metabolize a larger share of nicotine. Thus, glucuronidation may become a more significant factor in overall nicotine metabolism. Slower metabolism of nicotine means that levels of nicotine in the body remain elevated for a longer period of time, allowing a longer timeframe for nicotine to interact with nicotinic receptors all over the body.

The authors of a small cross-over study of seven Black/African American and seven White smokers found that menthol cigarette smoking resulted in slower nicotine metabolism and slower total nicotine clearance. Overall, there were no significant racial/ethnic differences in the disposition kinetics of nicotine [7]. Menthol cigarette smoking was associated with reduced nicotine metabolism through a decrease in CYP2A6 enzyme activity and a substantial reduction in glucuronidation. These findings were supported in an in vitro study using human microsomes that reported that menthol inhibits the CYP2A6 enzyme, resulting in inhibition of nicotine metabolism [8].
Using data from a study of 755 Black/African American smokers who smoked fewer than 10 cigarettes a day (so-called "light" smokers), Ho and colleagues [9] found that smokers who smoke menthol cigarettes had slower metabolism of cotinine as compared to non-menthol smokers.

Clark et al [10] studied the effects of menthol cigarettes on biochemical markers of smoke exposure among 161 adult Black/African American and White smokers in a cross-sectional study. There were also racial/ethnic differences, with African American smokers having significantly higher cotinine per cigarette ratios, but it is unknown if this is due to differences in metabolism, smoking behavior, or other reasons. After adjusting for race, cigarettes per day and average amount of each cigarette smoked, serum cotinine levels were significantly higher among menthol cigarette smokers than among smokers of non-menthol cigarettes, suggesting greater exposure to nicotine. [10] Numerous other reports [4,10-15] have found that Black/African American smokers are more likely than White smokers to smoke fewer cigarettes per day (CPD) yet have substantially higher cotinine levels. Because Black/African American individuals are considerably more likely to smoke menthol cigarettes, menthol may have been a mitigating factor; however, the potential impact of menthol was not evaluated separately in these studies.

In a between-subjects study of 95 female adult smokers stratified by race/ethnicity and menthol/nonmenthol cigarette preference, Ahijevych and Parsley [11] reported that smokers of menthol cigarettes had higher cotinine levels. This finding would be expected, given menthol's inhibition of CYP2A6 metabolism and glucuronidation $[8,16,17]$. As was found with Clark et al [10], Black/African American subjects had higher cotinine per cigarette levels, suggesting greater exposure to nicotine.

Data from the National Health and Nutrition Examination Survey (NHANES) were used to compare the serum cotinine levels of more than 1,500 smokers. The data from this large, nationally representative sample compared menthol and non-menthol smokers. Menthol smokers were found to have significantly higher serum cotinine levels $(1333.8 \pm 40.1 \mathrm{nmol} / \mathrm{L})$ as compared to non-menthol smokers $(1230.3 \pm 24.5 \mathrm{nmol} / \mathrm{L})$ [6].

In an inpatient research study by Ahijevych and colleagues [4], plasma samples were taken while the subjects were smoking as desired, followed by several days of smoking abstinence. Cotinine half-life and did not significantly differ between menthol (23.1 \pm 7.9 hours) and non-menthol smokers $(18.1 \pm 8.1$ hours $)$ [4]. However, as has been discussed previously $[10,11]$, there was a main effect for race, with Black/African American smokers having greater cotinine levels as compared to 
white smokers. Again, this suggests that these people had greater exposure to nicotine on a per cigarette basis.

A study by Patterson et al (2003) of 190 treatmentseeking smokers (29 menthol smokers, 161 non-menthol smokers) failed to find significant differences in nicotine boost (an individualized measure of how much nicotine has been extracted from smoking a cigarette) produced following the smoking a preferred-brand cigarette $(\mathrm{p}<$ $0.10)$. However, the authors note that "the absence of racial differences in boost and a lack of association with cigarette characteristics (e.g., menthol) may be attributable to the relatively small number of African Americans in the sample" [18]. Consistent with other studies $[4,10,11]$, being Black/African American was significantly associated with greater levels of blood nicotine following a single cigarette. [18]

Mustonen et al [19] investigated possible associations between cotinine/CPD ratios in subgroups varying by gender and race/ethnicity in a randomized clinical trial. Consistent with other studies $[4,10,11,18]$, Black/African American smokers smoked fewer CPD, but did not have significantly lower cotinine levels, suggesting a higher cotinine per cigarette ratio. Although there was a pattern toward higher cotinine levels in smokers of menthol cigarettes, it was not statistically significant. There was, however, a significant gender by race by menthol interaction on salivary cotinine level as well as cotinine/CPD ratio. Black/African American menthol cigarette smokers and Black/African American nonmenthol cigarette smoking women had higher cotinine/ CPD ratios than did White smokers. These findings suggest that the relationship between number of cigarettes consumed and salivary cotinine is complex. This study was limited in that puffing rate, depth of inhalation and length of cigarette smoked could not be controlled for in the study sample. The authors concluded that type of cigarette, race/ethnicity, and gender need to be evaluated concurrently [19].

Wang et al [20] investigated the effects of menthol cigarettes on adult smokers' exposure to nicotine in a large, cross-sectional study. The menthol cigarette smokers were more likely to be Black/African American and more likely to be female, which is consistent with the demographics in other studies (for review, see Ahijevych and Garrett 2004 [21]). There were no significant differences in nicotine equivalents (nicotine and five major nicotine metabolites) per cigarette, leading the researchers to conclude that smoking menthol cigarettes does not increase daily exposure to smoke constituents. No significant differences were found in serum cotinine levels between menthol and non-menthol cigarette smokers, suggesting that menthol had no effect on the metabolism of nicotine in the study. Consistent with other studies $[4,10,11,18,19]$, although the Black/African
American smokers smoked fewer cigarettes per day, there was no different in serum cotinine levels, suggesting a higher nicotine/cigarette ratio. One limitation of the study was that only a small proportion of the Black/ African American smokers smoked non-menthol cigarettes.

In a tobacco industry-associated parallel arm study designed to investigate whether moderately heavy $(\geq 15$ CPD) smokers of menthol cigarettes had different biomarker levels than non-menthol cigarette smokers, the researchers failed to find significant differences in urine levels of nicotine or glucuronidated nicotine metabolites. Unlike other studies $[4,10,11,18,19]$, they found no significant racial/ethnic differences in metabolism [22]. A limitation of the study was the small number of Black/ African American non-menthol cigarette smokers compared with the number of White non-menthol cigarette smokers.

Using a stored sample from 255 current smokers from the Southern Community Cohort Study (65 Black/African American men, 65 Black/African American women, 63 White men, 62 White women), comparisons of serum cotinine levels of menthol and non-menthol smokers were made. There were significant interactions between gender and race/ethnicity, but no significant differences were found between menthol and nonmenthol groups [23]. Consistent with previous studies $[4,10,11,18,19]$, after adjustment for CPD differences, Black/African American smokers had higher cotinine levels as compared to white smokers.

In a study of more than 700 Black/African American light smokers $(\leq 5 \mathrm{CPD})$, menthol smokers did not differ in plasma cotinine levels when compared to their nonmenthol smoking counterparts. This may be due to a wide range between the minimum and maximum plasma cotinine levels across smokers in the study: 5.0 $\mathrm{ng} / \mathrm{mL}$ versus $937.8 \mathrm{ng} / \mathrm{mL}[9]$.

A study by Williams and colleagues [24] compared cotinine levels of menthol- and non-menthol-smoking patients with and without schizophrenia. The laboratory study of 142 people assessed blood cotinine levels during a typical smoking day, two minutes after smoking a usual-brand cigarette. There were no significant differences when comparing the schizophrenic smokers with non-schizophrenic smokers. However, menthol smokers had significantly higher serum cotinine levels as compared to non-menthol smokers $(294.3 \mathrm{ng} / \mathrm{ml}$ and 238.8 $\mathrm{mg} / \mathrm{ml}$, respectively; $\mathrm{p}=.041)$. Menthol smokers also had significantly higher serum nicotine levels $(27.2 \mathrm{mg} /$ $\mathrm{ml}$ and $22.4 \mathrm{mg} / \mathrm{ml}$, respectively; $\mathrm{p}=0.01$ ) an effect that appears to be driven by schizophrenic smokers having significantly higher serum nicotine levels as compared to non-schizophrenic smokers $(\mathrm{p}<0.05)$. The authors suggest that the elevated levels observed in menthol 
smokers may be due in part to increased intake of smoke or menthol-mediated inhibition of nicotine metabolism [24].

\section{Carbon monoxide}

Like the nicotine/cotinine data, the data from studies measuring expired air carbon monoxide $(\mathrm{CO})$ and/or levels of blood carboxyhemoglobin (a measure of $\mathrm{CO}$ exposure), which are often used as biomarkers to indicate level of exposure to tobacco smoke, are not consistent. Some investigators have found that menthol cigarette smoking increased $\mathrm{CO}$ (as measured by expired $\mathrm{CO}, \mathrm{CO}$ boost, or blood carboxyhemoglobin) as compared to non-menthol cigarettes smoke [10,24-26], whereas other studies, including one associated with the tobacco industry, have found either no difference in $\mathrm{CO}$ exposure [22,26-29], or a lower level among menthol smokers [30,31]. Ahijevych et al (1996) that found that menthol smokers had lower CO measurements as compared to non-menthol smokers, reporting statistically significant differences for the Black/African American menthol participants of this women-only study [30]. Possible reasons for the inconsistency of the findings include the possibility that physiologic variables, such as mucous layers in mucosal cold nerve endings or differences in how the cigarette burns (menthol pyrolysis) may affect CO levels $[30,32]$. Also, menthol's effects on biomarkers such as blood carboxyhemoglobin and cotinine are not linear and, as has been noted by publicly available internal tobacco industry documents, are affected by other chemicals in the smoke [33].

\section{Tobacco-specific nitrosamines}

Toxins present in tobacco, such as tobacco-specific nitrosamines (TSNAs), which are known carcinogens, are also used as biomarkers of tobacco smoke exposure. Menthol may alter glucuronidation metabolism of some TSNAs, such as the tobacco carcinogen, 4-(methylnitrosamino)-1-(3-pyridyl)-1-butanone; (NNAL), which goes through a glucuronic metabolic pathway to form NNAL-Glucuronide (NNAL-Gluc) [16]. Thus, inhibition of the glucuronidation process may result in adverse effects, such as an accumulation of NNAL.

As a parallel to the findings by MacDougall et al [8] in an experimental in vitro study, Muscat et al [16] found that menthol inhibited glucuronidation of NNAL in human microsomes; however, in an in vivo study of rats treated with 4-(methylnitrosamino)-1-(3-pyridyl)-1-butanone, or NNK (a TSNA that is metabolized into the TSNA NNAL), those that received oral menthol showed increased levels of NNAL metabolites. This suggests enhanced metabolism. Orally administered menthol delivered in the absence of the other constituents of tobacco smoke, as well as generalizing from rats to humans, makes generalizations regarding the possible effects of menthol tobacco smoke difficult.

In an in vivo component of the Muscat et al [17] study mentioned above, urinary ratios of NNAL/NNALGluc in adult smokers were measured. Smokers of menthol cigarettes had lower urinary ratios of NNAL/ NNAL-Gluc than smokers of non-menthol cigarettes, suggesting that menthol inhibited NNAL glucuronidation [17]. Although these findings provide additional support that menthol generally inhibits glururonidation $[7,8]$ a tobacco industry associated study failed to find any inhibition of glucuronidation of NNAL [22]. This parallel-arm study, which measured levels of total NNAL and NNAL-gluc in the urine of moderately heavy ( $\geq 15$ CPD) smokers of "light" cigarettes (7-15 mg Federal Trade Commission [FTC] "tar"), failed to find significant differences when comparing levels in menthol versus non-menthol smokers [21]. Differences in urinary metabolites of NNAL between Black/African American and White smokers have been found in other studies, but menthol was not specifically investigated as the cause of these differences [34].

\section{Toxicity and cellular effects}

A tobacco industry associated study exposed rats to menthol or non-menthol cigarette smoke via nose-inhalation for 1 hour a day, five days per week for 13 weeks. Exposure to either type of cigarette smoke produced reduced body weights and histopathological changes, including epithelial hyperplasia and/or squamous metaplasia in the nasal passages, trachea and larynx, and lungs and bronchi. Olfactory epithelial degeneration was also observed. There were no differences in these changes between the types of cigarette smoke. The only difference noted between the two groups of rats was that the non-menthol tobacco smoke-exposed rats had a dose-related increase in nasal discharge [35].

Menthol appears to alter cell membranes, and the findings of animal studies have suggested, according to some, that these changes in cell membrane integrity may result in an increased potential for tobacco-related disease [36]. In a study evaluating tobacco smoke effects on transepithelial electrical resistance (TER; the tight gap junctions between the human bronchial epithelial cells), both non-menthol and menthol smoke reduced TER. This indicates that the gap junctions between the cells were "loosened" up and integrity was lost, which suggests that the smoke irritated these cells. Menthol did not appear alter this effect of tobacco smoke [37]. It does appear, however, that menthol alters cells' permeability. Porcine esophageal tissue bathed in a solution containing menthol and NNK had a markedly lower permeation rate for NNK, and produced an increase in tissue reservoir formation. This resulted in significantly 
more NNK bound within the esophageal mucosa, possibly increasing cell exposure to NNK, which is something that the authors suggest may increase the likelihood of cancer of the esophagus [36]. Recently, menthol has been shown to increase permeation of both the tobacco carcinogen nitrosonornicotine (NNN) and nicotine across porcine buccal mucosa and floor of the mouth mucosa [39], which suggests menthol could increase exposure to NNN and nicotine. It should be noted that epidemiological studies on menthol cigarettes and cancer risk do not support the proposition that these cigarettes confer a risk for cancer above that of non-menthol cigarettes (see "Tobacco-Related Disease").

One of the more immediate cellular effects of menthol on cell membranes is that of cell death (cytotoxicity). Menthol has been shown to be toxic in in vitro biologic model systems in normal tissue: it inhibits fatty acidinduced (receptor-mediated) cell respiration in brown adipose tissue and increased cellular respiration rate and osmotic swelling (suggesting deterioration of biologic membranes) in mitochondria [39]. In a variety of cancer cell cultures, including gastric SNU-5 cells, melanoma, myeloma, liver epithelial, neuroendocrine, bladder, and leukemia cells, as well as cells associated with prostate cancer and neuroblasoma cells, menthol dose- and timedependently inhibits cell proliferation and/or induces cell death [40-51]. Although there is much evidence suggesting toxicity, it is important to note that this is not a universal finding (see Gordon et al 1982 [52]). Despite indications of menthol-induced cytotoxicity in both normal and diseased cells, when added to cigarettes, menthol does not appear to enhance the cytotoxicity already produced by tobacco smoke exposure. According to five tobacco industry associated research studies, both menthol and non-menthol cigarette smoke have similar levels of cytoxicity, based on results of shortterm genotoxicity assays [53-57].

\section{Lung function and respiration}

On two separate days, 74 smokers (18 menthol smokers, 56 non-menthol smokers) participating in an in-patient study were allowed to smoke one of their usual brand of cigarettes. During this time, their breathing patterns were measured. This tobacco industry associated study found that the average inhalation tidal ratio (a measure of lung volume) was 1.52 for menthol smokers and 1.79 for the non-menthol smokers, which suggested menthol smokers had lower inhalation tidal ratios $(\mathrm{p}=0.054)$. Mean inhalation volume for menthol smokers was 753 $\mathrm{mL}$, which was lower than for non-menthol smokers, but this difference was not statistically significant ( $\mathrm{p}=$ 0.11 ). Total lung exposure times did not significantly differ between menthol and non-menthol smokers (4.0 sec and $4.1 \mathrm{sec}$, respectively; $\mathrm{p}=0.85$ ) [58].
Smokers with mild-to-moderate chronic obstructive pulmonary disease were recruited into the longitudinal Lung Health Study. A total of 5,886 smokers participated in this prospective, randomized smoking cessation trial. Although demographic and population information did not include information on the number of smokers who smoked menthol cigarettes or non-menthol cigarettes, it was reported that smoking menthol cigarettes did not significantly affect the rate of decline in lung function in Year $1(\mathrm{p}=0.229)$ or between Year 1 and Year $5(\mathrm{p}=0.64)$, as measured by spirometry, a modified ATS-DLD-78 Respiratory Symptoms Questionnaire, and a calculated methacholine reactivity score (based on forced expiratory volume). No other comparisons of menthol and non-menthol smokers were reported [59].

According to a published analysis of publicly available internal tobacco industry documents, when added to cigarettes, menthol enables deeper inhalation and may alter the frequency or volume of inhalation patterns [60]. Most studies, however, have failed to find any effects of menthol on respiration (e.g., breathing patterns, nasal resistance). However, despite a lack of physiological effects, inhaled menthol vapor has been associated with reduced ratings of respiratory discomfort [61-63]. The dichotomy between sensation and physiological response has been noted by the tobacco industry, which (according to one published analysis of publicly available internal tobacco industry documents) has concluded that menthol increases the perception of nasal openness in the absence of actual changes in nasal resistance [60].

\section{Cardiovascular function}

Data collected in the longitudinal Coronary Artery Risk Development in Young Adults (CARDIA) study was used to prospectively evaluate the effects of cigarette smoking on atherosclerosis and pulmonary function. This large scale, 15-year study of Black/African American and White Americans found that menthol and nonmenthol cigarettes were equally harmful. Smokers of either type of cigarette had increased prevalence of coronary calcification and reduced pulmonary function [64].

In a rapid-smoking study, there was one racial/ethnic difference in the cardiovascular response of menthol versus non-menthol smokers in response to exposure to menthol cigarette smoke. In this repeated-measures laboratory study of 28 smokers, Black/African American menthol smokers had lower increases in heart rate following inhalation of menthol cigarette smoke as compared to Black/African American non-menthol smokers ( $4.4 \%$ increase and $12.2 \%$ increase, respectively). The increases in heart rate of Black/African American menthol and non-menthol smokers did not significantly 
differ following inhalation of non-menthol cigarette smoke [65].

Three laboratory cross-over studies by Ciftci and colleagues assessed various cardiovascular outcomes following the smoking of two test cigarettes (menthol or nonmenthol). Following the smoking of menthol cigarettes, there were generally worse cardiovascular outcomes, including worse ventricular diastolic function [66], greater increases in heart rate $(101.2 \mathrm{bpm}$ compared to $83 \mathrm{bpm})$, greater increase in systolic blood pressure (130.7 $\mathrm{mmHG}$ compared to $118.0 \mathrm{mmHg}$ ), and greater stiffness of the carotid artery (stiffness index of 5.7 compared to 2.2) [67]; however, there was no difference on measures of coronary flow reserve [68]. It is not known whether the participants were usually menthol or nonmenthol smokers.

In a small cross-over laboratory study $(n=22)$, the effects of "denicotinized" test menthol and non-menthol cigarettes on a range of psychophysiologic and subjective variables were measured in both menthol and nonmenthol smokers. No differences between the groups were found with respect to most of the variables, although menthol smokers were found to have a greater increase in heart rate after smoking the test cigarettes as compared to non-menthol smokers. Menthol smoke itself did not have any effects that differed from nonmenthol smoke; however, menthol smokers had greater increases in heart rate, regardless of test cigarette, as compared to non-menthol smokers [69]. This appears to be a smoker difference rather than a menthol versus non-menthol cigarette difference. Since the nicotine had been removed from the test denicotinized menthol and non-menthol cigarettes, this suggests that menthol smokers may be more sensitive to non-nicotinic, and even non-menthol, components of smoking, such as other chemical components or sensory cues.

\section{Tobacco-related disease}

\section{Basic research}

Basic research has not found evidence that menthol, by itself, causes cancer or is mutagenic [70-74]. It may, however, affect cancers induced by other chemicals. Three animal studies investigated the effects of menthol on cancer. A tobacco industry associated study found that menthol cigarette smoke condensate painted on mouse skin did not significantly alter tumor incidence, latency, or multiplicity as compared to non-menthol cigarette smoke condensate. Both menthol and nonmenthol cigarette smoke condensate produced 3-11 tumors per mouse [75]. A second study examined the effect of orally administered menthol on cancer of the large bowel and duodenum in rats, and found that menthol did not significantly alter the percent of rats with tumors $(50 \%$ of control rats, $42 \%$ of menthol- treated rats ) or number of tumors per rat (1.5 tumors in control rats and 1.2 tumors in menthol-treated rats) [76]. A third study also examined the effect of orally administered menthol on carcinogenesis. In a rat mammary carcinogenesis model, rats treated with orally administered menthol had fewer average number of tumors per rat (2.0 as compared with 3.3), as well as longer median tumor latencies ( 80 days as compared with 63 days). These data suggest that menthol inhibited carcinogenesis and acted as a chemopreventive agent that extended tumor latency [77]. As has been previously discussed, generalization is difficult, as orally administered menthol differs greatly from menthol inhaled as a constituent of tobacco smoke.

\section{Clinical and epidemiological research}

Possible interactions between menthol and smokingrelated disease, either as a disease state or on the cellular level, have been studied. The data do not suggest that smoking menthol cigarettes is associated with an altered likelihood of developing cancer. Several studies have failed to find that menthol cigarette smoking alters the likelihood of developing several kinds of cancers, including lung and non-lung smoking related cancers, as well as cardiovascular disease or coronary heart disease [78-80] in the population as a whole.

Although some studies specifically discussed the absence of a menthol $\mathrm{x}$ gender $\mathrm{x}$ disease interaction $[77,80]$, other studies have suggested that such an interaction may exist. One prospective study of the health of smokers found that male (but not female) menthol smokers had a modestly increased risk of lung cancer, with a relative risk of $1.45(95 \% \mathrm{CI}=1.03-2.02)$ [82]. Another case control study suggested a small positive association between pharyngeal cancer in mentholsmoking males, but not females $(\mathrm{OR}=1.7 ; 95 \% \mathrm{CI}=$ $0.8-3.4$ ), but this difference was not statistically significant [84]. A third case control study found that menthol use was not associated with changes in risk for esophageal cancer in males, but suggested that females may have a modestly increased risk $(\mathrm{OR}=2.3 ; 95 \% \mathrm{CI}=$ 0.93-5.72). These differences also failed to reach statistical significance [85]. A fourth case control study suggested that menthol may modestly increase risk of lung cancer in men with histories of more than 32 pack years of smoking menthol cigarettes $(\mathrm{OR}=1.48 ; 95 \% \mathrm{CI}=$ $0.71-3.05)$, but the findings were not statistically significant and limited by the small study size [86].

Many studies have compared Black/African American smokers with White smokers, finding consistently that the Black/African American smokers are at higher risk for tobacco-related disease such as lung cancer [87]. These studies, however, failed to separately assess menthol as a contributing factor, so although menthol 
was discussed as a possible mitigating factor, no conclusions could be drawn. Although not discussing menthol per se, an article by Etzel and colleagues [88] suggested that the lung cancer risk prevention model that is generally used may not be appropriate for Black/African American populations, since the models were developed in White populations. This is an interesting concept that is included here for discussion purposes, since menthol preference is more common among Black/African American smokers as compared to White smokers. Etzel et al developed a multivariate model of predicting risk of lung cancer in the black population. Using their model, they state that "mentholated cigarettes seemed to be protective in current smokers" [88]; however, this finding was not statistically significant [88].

\section{Summary}

Menthol is a biologically active compound that interacts with tobacco constituents such as nicotine and NNAL, and may damage or kill cells. Key findings include:

- Data on menthol's effects on biomarkers of smoke exposure, including nicotine/cotinine, $\mathrm{CO}$ (expired $\mathrm{CO}$, blood carboxyhemoglobin), and some TSNAs are inconclusive.

- Menthol is a biologically active compound that may damage or kill cells.

- Menthol does not appear to alter the cytotoxic effects of tobacco smoke.

- Menthol reduces feelings of respiratory discomfort, but there are no corresponding physiological effects.

- The data regarding the effect of menthol on cardiovascular responses to cigarette smoke are inconclusive, however there is some evidence that smoking menthol cigarettes may produce worse cardiovascular effects as compared to nonmenthol cigarettes.

- Overall, the data regarding menthol cigarette smoke and cancer do not support a link between menthol cigarette smoke and increased risk of cancer, however there are some limited data that suggest possible menthol $\mathrm{x}$ gender $\mathrm{x}$ disease interactions.

Thus, based on the data reviewed in this paper, menthol cigarettes do not generally appear to be more harmful than nonmenthol cigarettes; both cigarettes produce significant negative effects on health outcomes, including respiratory disease, cardiovascular outcomes and cancer. However, there is some indication that menthol cigarettes may result in worse acute cardiovascular outcomes. In addition, there may be subgroups of smokers that may be more or less sensitive to the health effects of smoking cigarettes (e.g., race $x$ gender $x$ menthol interactions). It is interesting to note that although there were some indications that menthol smokers may be harmed more by cigarette smoking as compared to nonmenthol smokers, there were no indications of the converse.

\section{Acknowedgement}

Disclaimer: This article reflects the views of the author and should not be construed to represent FDA's views or policies.

This article has been published as part of Tobacco Induced Diseases Volume 9 Supplement 1, 2011: Mentholated cigarettes and public health. Publication of this supplement has been supported by the Center for Tobacco Products, Food and Drug Administration. The full contents of the supplement are available online at http://www.tobaccoinduceddiseases.com/supplements/9/S1

\section{Competing interests}

The author declares that they have no competing interests.

\section{Published: 23 May 2011}

\section{References}

1. Centers for Disease Control and Prevention: Smoking-attributable mortality, years of potential life lost, and productivity losses-United States, 2000-2004. Morbidity and Mortality Weekly Report 2008, 57(45):1226-1228.

2. U.S. Department of Commerce Census Bureau: National Cancer Institute and Centers for Disease Control and Prevention Co-sponsored Tobacco Use Supplement to the Current Population Survey (2006-07)., Available at: http://riskfactor.cancer.gov/studies/tus-cps/info.html.

3. Giovino GA, Sidney S, Gfroerer JC, et al: Epidemiology of menthol cigarette use. Nicotine Tob. Res 2004, 6(Suppl 1):S67-81.

4. Ahijevych $\mathrm{KL}$, Tyndale RF, et al: Factors influencing cotinine half-life during smoking abstinence in African American and Caucasian women. Nicotine and Tobacco Research 2002, 4(4):423-431.

5. Caraballo RS, Giovino GA, et al: Racial and ethnic differences in serum cotinine levels of cigarette smokers-Third National Health and Nutrition Examination Survey, 1988-1991. JAMA 1998, 280(2):135-139.

6. Gan WQ, Cohen SB, et al: Sex-related differences in serum cotinine concentrations in daily cigarette smokers. Nicotine and Tobacco Research 2008, 10(8):1293-1300.

7. Benowitz NL, Herrera B, Jacob P: Mentholated cigarette smoking inhibits nicotine metabolism. J Pharmacol Exp Ther 2004, 310(3):1208-1215.

8. MacDougall JM, Fandrick $K$, et al: Inhibition of human liver microsomal (S)-nicotine oxidation by (-)-menthol and analogues. Chemical Research in Toxicology 2003, 16(8):988-993.

9. Ho MK, Mwenifumbo JC, Al Koudsi N, Okuyemi KS, Ahluwalia JS, Benowitz NL, Tyndale RF: Association of nicotine metabolite ratio and CYP2A6 genotype with smoking cessation treatment in AfricanAmerican light smokers. Clin Pharmacol Ther 2009, 85(6):635-643.

10. Clark PI, Gautam S, et al: Effect of menthol cigarettes on biochemical markers of smoke exposure among black and white smokers. Chest 1996, 110(5):1194-1198.

11. Ahijevych K, Parsley LA: Smoke constituent exposure and stage of change in Black and White women cigarette smokers. Addictive Behaviors 1999, 24(1):115-120.

12. Ahijevych K, Wewers ME: Factors associated with nicotine dependence among African American women cigarette smokers. Research in Nursing and Health 1993, 16(4):283-292.

13. Henningfield JE, Benowitz NL, et al: Does menthol enhance the addictiveness of cigarettes? An agenda for research. Nicotine and Tobacco Research 2003, 5(1):9-11.

14. Perez-Stable EJ, Herrera B, et al: Nicotine metabolism and intake in Black and White smokers. JAMA 1998, 280(2):152-156.

15. Wagenknecht LE, Cutter GR, et al: Racial differences in serum cotinine levels among smokers in the Coronary Artery Risk Development in (Young) Adults study. American Journal of Public Health 1990, 80(9):1053-1056.

16. Benowitz NL: Clinical pharmacology of nicotine: implications for understanding, preventing, and treating tobacco addiction. Clinical Pharmacology and Therapeutics 2008, 83(4):531-541. 
17. Muscat JE, Chen $G$, et al: Effects of menthol on tobacco smoke exposure, nicotine dependence, and NNAL Glucuronidation. Cancer Epidemiol Biomarkers Prev 2009, 18(1):35-41.

18. Patterson F, et al: Individual Differences in Nicotine Intake Per Cigarette. Cancer Epidemiol Biomarkers Prev 2003, 12:468-471.

19. Mustonen TK, Spencer SM, et al: The influence of gender, race, and menthol content on tobacco exposure measures. Nicotine and Tobacco Research 2005, 7(4):581-590.

20. Wang J, Roethig HJ, et al: The effect of menthol containing cigarettes on adult smokers' exposure to nicotine and carbon monoxide. Regul Toxicol Pharmacol 2010, 57(1):24-30.

21. Ahijevych K, Garrett BE: Menthol pharmacology and its potential impact on cigarette smoking behavior. Nicotine and Tobacco Research 2004, 6(suppl 1):S17-S28.

22. Heck JD: Smokers of menthol and nonmenthol cigarettes exhibit similar levels of biomarkers of smoke exposure. Cancer Epidemiol Biomarkers Prev 2009, 18(2):622-629.

23. Signorello $L, C a i$, et al: Racial differences in serum cotinine levels of smokers. Dis Markers 2009, 27(5):187-192.

24. Williams JM, Gandhi KK, Steinberg ML, Foulds J, Ziedonis DM, Benowitz NL: Higher nicotine and carbon monoxide levels in menthol cigarette smokers with and without schizophrenia. Nicotine and Tobacco Research 2007, 9(8):873-881.

25. Jarvik ME, Tashkin DP, et al: Mentholated cigarettes decrease puff volume of smoke and increase carbon monoxide absorption. Physiology and Behavior 1994, 56(3):563-70.

26. Miller $\mathrm{GE}$, Jarvik $M E$, et al: Cigarette mentholation increases smokers' exhaled carbon monoxide levels. Experimental and Clinical Psychopharmacology 1994, 2(2):154-160.

27. Caskey NH, Jarvik ME, et al: Rapid smoking of menthol and nonmenthol cigarettes by Black and White smokers. Pharmacol Biochem Behav 1993, 46(2):259-263.

28. McCarthy WJ, Caskey NH, et al: Menthol vs. nonmenthol cigarettes: effects on smoking behavior. American Journal of Public Health 1995, 85(1):67-72.

29. Nil R, Battig K: Separate effects of cigarette smoke yield and smoke taste on smoking behavior. Psychopharmacology (Berl) 1989, 99(1):54-59.

30. Ahijevych K, Gillespie J, et al: Menthol and nonmenthol cigarettes and smoke exposure in Black and White women. Pharmacol Biochem Behav 1996, 53(2):355-360.

31. Rosenblatt MR, Olmstead RE, Iwamoto-Schaap PN, Jarvik ME: Olfactory thresholds for nicotine and menthol in smokers (abstinent and nonabstinent) and nonsmokers. Physiology and Behavior 1998, 65(3):575-9.

32. Schmeltz I, Schlotzhauer WS: Benzo(a)pyrene, phenols and other products from pyrolysis of the cigarette additive, (d,1)-menthol. Nature 1968, 219(5152):370-371

33. Rabinoff M, Caskey N, et al: Pharmacological and chemical effects of cigarette additives. American Journal of Public Health 2007, 97(11):1981-1991.

34. Richie JP Jr, Carmella SG, et al: Differences in the urinary metabolites of the tobacco-specific lung carcinogen 4-(methylnitrosamino)-1-(3-pyridyl)1-butanone in Black and White smokers. Cancer Epidemiol Biomarkers Prev 1997, 6(10):783-790.

35. Gaworski CL, Dozier MM, et al: 13-week inhalation toxicity study of menthol cigarette smoke. Food and Chemical Toxicology 1997, 35(7):683-692.

36. Azzi C, Zhang J, et al: Permeation and reservoir formation of 4(methylnitrosamino)-1-(3-pyridyl)-1-butanone (NNK) and benzo[a]pyrene (B[a]P) across porcine esophageal tissue in the presence of ethanol and menthol. Carcinogenesis 2006, 27(1):137-145.

37. Alakayak J, Knall C: Mentholated and non-mentholated cigarettes alter transepithelial electrical resistance of calu-3 human bronchial epithelial cells. Ethnicity and Disease 2008, 18(2 suppl 1):S145-S146.

38. Squier CA, Mantz MJ, Wertz PW: Effect of menthol on the penetration of tobacco carcinogens and nicotine across porcine oral mucosa ex vivo. Nicotine and Tobacco Research 2010, e-pub ahead of print.

39. Bernson VS, Pettersson B: The toxicity of menthol in short-term bioassays. Chemico-Biological Interactions 1983, 46(2):233-246.

40. Bernhardt $G$, Biersack $B$, et al: Terpene conjugates of diaminedichloridoplatinum(II) complexes: antiproliferative effects in $\mathrm{HL}$ 60 leukemia, 518A2 melanoma, and HT-29 colon cancer cells. Chemistry and Biodiversity 2008, 5(8):1645-1659.
41. Kim SH, Nam JH, et al: Menthol regulates TRPM8-independent processes in PC-3 prostate cancer cells. Biochimica et Biophysica Acta 2009, 1792(1):33-38

42. Li $Q$, Wang $X$, et al: Menthol induces cell death via the TRPM8 channel in the human bladder cancer cell line T24. Oncology 2009, 77:335-341.

43. Lin JP, Lu HF, et al: (-)-Menthol inhibits DNA topoisomerases I, II alpha and beta and promotes NF-kappaB expression in human gastric cancer SNU-5 cells. Anticancer Research 2005, 25(3B):2069-2074.

44. Lu HF, Hsueh SC, et al: The role of $\mathrm{Ca} 2+$ in (-)-menthol-induced human promyelocytic leukemia HL-60 cell death. In Vivo 2006, 20(1):69-75.

45. Lu HF, Liu JY, et al: (-)-Menthol inhibits WEHI-3 leukemia cells in vitro and in vivo. In Vivo 2007, 21(2):285-289.

46. Ruch RJ, Sigler K: Growth inhibition of rat liver epithelial tumor cells by monoterpenes does not involve Ras plasma membrane association. Carcinogenesis 1994, 15(4):787-789.

47. Sidell N, Verity MA, et al: Menthol blocks dihydropyridine-insensitive Ca2+ channels and induces neurite outgrowth in human neuroblastoma cells. Journal of Cellular Physiology 1990, 142(2):410-419.

48. Sidell N, Taga T, et al: Retinoic acid-induced growth inhibition of a human myeloma cell line via down-regulation of IL-6 receptors. J Immunol 1991, 146(11):3809-3814.

49. Tatman $\mathrm{D}, \mathrm{Mo} \mathrm{H}$ : Volatile isoprenoid constituents of fruits, vegetables and herbs cumulatively suppress the proliferation of murine B16 melanoma and human HL-60 leukemia cells. Cancer Letters 2002, 175(2):129-139.

50. Yamamura H, Ugawa S, et al: TRPM8 activation suppresses cellular viability in human melanoma. American Journal of Physiology: Cell Physiology 2008, 295(2):C296-C301.

51. Zhang L, Barritt GJ: Evidence that TRPM8 is an androgen-dependent $\mathrm{Ca} 2$ + channel required for the survival of prostate cancer cells. Cancer Research 2004, 64(22):8365-8373.

52. Gordon WP, Forte AJ, et al: Hepatotoxicity and pulmonary toxicity of pennyroyal oil and its constituent terpenes in the mouse. Toxicology and Applied Pharmacology 1982, 65(3):413-424.

53. Doolittle DJ, Lee CK, et al: Comparative studies on the genotoxic activity of mainstream smoke condensate from cigarettes which burn or only heat tobacco. Environmental and Molecular Mutagenesis 1990, 15(2):93-105.

54. Doolittle DJ, Lee CK, et al: Genetic toxicology studies comparing the activity of sidestream smoke from cigarettes which burn or only heat tobacco. Mutation Research 1990, 240(2):59-72.

55. Lee CK, Doolittle DJ, et al: Comparative genotoxicity testing of mainstream whole smoke from cigarettes which burn or heat tobacco. Mutation Research 1990, 242(1):37-45.

56. Roemer E, Tewes FJ, Meisgan TJ, et al: Evaluation of the potential effects of ingredients added to cigarettes. Part 3 : In vitro genotoxcity and cytotoxicity. Food and Chemical Toxicology 2002, 40:105-111.

57. Baker RR, Massey ED, Smith G: An overview of the effects of tobacco ingredients on smoke chemistry and toxicity. Food Chem Toxicol 2004, 42 Suppl:S53-S83.

58. Saint Charles FK, Krautter GR, Mariner DC: Post-puff respiration measures on smokers of different tar yield cigarettes. Inhalation Toxicology 2009, 21(8):712-718.

59. Scanlon PD, Connett JE, et al: Smoking cessation and lung function in mild-to-moderate chronic obstructive pulmonary disease: the lung health study. American Journal of Respiratory and Critical Care Medicine 2000, 161:381-390

60. Wayne GF, Connolly GN, et al: Assessing internal tobacco industry knowledge of the neurobiology of tobacco dependence. Nicotine and Tobacco Research 2004, 6(6):927-940.

61. Eccles $R$, Lancashire $B$, et al: The effect of aromatics on inspiratory and expiratory nasal resistance to airflow. Clinical Otolaryngology and Allied Sciences 1987, 12(1):11-14.

62. Eccles $R$, Jawad MS, et al: The effects of oral administration of (-)-menthol on nasal resistance to airflow and nasal sensation of airflow in subjects suffering from nasal congestion associated with the common cold. Journal of Pharmacy and Pharmacology 1990, 42(9):652-654.

63. Nishino T, Tagaito $Y$, et al: Nasal inhalation of I-menthol reduces respiratory discomfort associated with loaded breathing. American Journal of Respiratory and Critical Care Medicine 1997, 156(1):309-313.

64. Pletcher MJ, Hulley BJ, et al: Menthol cigarettes, smoking cessation, atherosclerosis, and pulmonary function: the Coronary Artery Risk 
Development in Young Adults (CARDIA) study. Archives of Internal Medicine 2006, 166(17):1915-1922.

65. Caskey NH, Jarvik ME, et al: Rapid smoking of menthol and nonmenthol cigarettes by Black and White smokers. Pharmacol Biochem Behav 1993, 46(2):259-263.

66. Ciftci O, Caliskan M, et al: Mentholated cigarette smoking induced alterations in left and right ventricular functions in chronic smokers. Anadolu Kardiyoloji Dergisi 2008, 8(2):116-122.

67. Ciftci O, Gullu H, et al: Mentholated cigarette smoking and brachial artery, carotid artery, and aortic vascular function. Archives of the Turkish Society of Cardiology 2009, 37(4):234-240.

68. Ciftci O, Topcu S, et al: Smoking mentholated cigarettes impairs coronary microvascular function as severely as does smoking regular cigarettes. Acta Cardiologica 2008, 63(2):135-140.

69. Pritchard WS, Houlihan ME, et al: Little evidence that "denicotinized" menthol cigarettes have pharmacological effects: an EEG/heart-rate/ sujective-response study. Psychopharmacology (Berl) 1999, 143(3):273-279.

70. National Cancer Institute: Bioassay of DL-Menthol for Possible Carcinogenicity. National Cancer Institute Carcinogenesis Technical Report Series No 98 (NCI-CG-TR-98) 1979.

71. Ashby J, Tennant RW: Definitive relationships among chemical structure, carcinogenicity and mutagenicity for 301 chemicals tested by the U.S. NTP. Mutat Res 1991, 257(3):229-306.

72. Ishidate M Jr, Sofuni T, Yoshikawa K, Hayashi M, Nohmi T, Sawada M, et al: Primary mutagenicity screening of food additives currently used in Japan. Food and Chemical Toxicology 1984, 22(8):623-636.

73. Ivett JL, Brown BM, Rodgers C, Anderson BE, Resnick MA, Zeiger E: Chromosomal aberrations and sister chromatid exchange tests in Chinese hamster ovary cells in vitro. IV. Results with 15 chemicals. Environmental and Molecular Mutagenesis 1989, 14:165-187.

74. Murthy PBK, Ahmed MM, Regu K: Lack of genotoxicity of menthol in chromosome aberration and sister chromatid exchange assays using human lynphocytes in vitro. Toxicology in Vitro 1991, 5(4):337-340.

75. Gaworski $\mathrm{CL}$, Heck JD, et al: Toxicologic evaluation of flavor ingredients added to cigarette tobacco: skin painting bioassay of cigarette smoke condensate in SENCAR mice. Toxicology 1999, 139(1-2):1-17.

76. Wattenberg LW: Inhibition of azoxymethane-induced neoplasia of the large bowel by 3-hydroxy-3,7,11-trimethyl-1,6,10-dodecatriene (nerolidol). Carcinogenesis 1991, 12(1):151-152.

77. Russin WA, Hoesly JD, et al: Inhibition of rat mammary carcinogenesis by monoterpenoids. Carcinogenesis 1989, 10(11):2161-2164.

78. Brooks DR, Palmer JR, et al: Menthol cigarettes and risk of lung cancer. American Journal of Epidemiology 2003, 158(7):609-616.

79. Friedman GD, Sadler M, et al: Mentholated cigarettes and non-lung smoking related cancers in California, USA. Journal of Epidemiology and Community Health 1998, 52(3):202.

80. Hebert JR, Kabat GC: Menthol cigarettes and esophageal cancer. American Journal of Public Health 1988, 78(8):986-987.

81. Kabat GC, Hebert JR: Use of mentholated cigarettes and lung cancer risk. Cancer Research 1991, 51(24):6510-6513.

82. Murray RP, Connett JE, Skeans MA, Tashkin DP: Menthol cigarettes and health risks in Lung Health Study data. Nicotine and Tobacco Research 2007, 9(1):101-107.

83. Sidney S, Tekawa IS, et al: Mentholated cigarette use and lung cancer. Archives of Internal Medicine 1995, 155(7):727-732.

84. Kabat GC, Hebert JR: Use of mentholated cigarettes and oropharyngeal cancer. Epidemiology 1994, 5(2):183-188.

85. Hebert JR, Kabat GC: Menthol cigarette smoking and oesophageal cancer. International Journal of Epidemiology 1989, 18(1):37-44.

86. Carpenter $C L$, Jarvik $M E$, et al: Mentholated cigarette smoking and lungcancer risk. Annals of Epidemiology 1999, , 2: 114-120.

87. Stellman SD, Chen Y, et al: Lung cancer risk in White and Black Americans. Annals of Epidemiology 2003, 13(4):294-302.

88. Etzel CJ, Kachroo S, et al: Development and validation of a lung cancer risk prediction model for African-Americans. Cancer Prevention Research 2008, 1(4):255-265.

89. Garten S, Falkner RV: Continual smoking of mentholated cigarettes may mask the early warning symptoms of respiratory disease. Preventive Medicine 2003, 37(4):291-296.
doi:10.1186/1617-9625-9-S1-S7

Cite this article as: Hoffman: The health effects of menthol cigarettes as compared to non-menthol cigarettes. Tobacco Induced Diseases 20119 (Suppl 1):S7.

\section{Submit your next manuscript to BioMed Central and take full advantage of:}

- Convenient online submission

- Thorough peer review

- No space constraints or color figure charges

- Immediate publication on acceptance

- Inclusion in PubMed, CAS, Scopus and Google Scholar

- Research which is freely available for redistribution

Submit your manuscript at www.biomedcentral.com/submit
Biomed Central 